\title{
CAMINOS DE LIBERACIÓN ANTE EL BICENTENARIO
}

Samuel Guerra Bravo*

\section{Resumen}

El trabajo que aquí se presenta plantea la necesidad de que la filosofía piense las condiciones de posibilidad de la liberación latinoamericana doscientos años después de las gestas independentistas del primer cuarto del siglo XIX. Para ello debe tener en cuenta tanto las determinaciones estructurales del sistema capitalista neo-liberal, como la tradición del pensamiento emancipador latinoamericano que viene desde Bartolomé de Las Casas. Actualmente se ven posibilidades de 'liberación' en nuestra re-constitución como sujetos, que superaría la condición de 'objetos a la mano' o 'valor de cambio' que nos asigna la 'colonialidad del ser, del poder y del saber'. Tal proceso de subjetivación conlleva una re-constitución ontológica, antropológica, epistemológica, ética y política y se considera que este es el camino correcto hacia nosotros mismos, hacia nuestra dignidad de seres humanos, pensantes, libres y ciudadanos. Se concluye que esta tarea re-constitutiva constituye un paso necesario para la anhelada 'segunda independencia'.

* Docente de la PUCE. 


\section{Introducción}

¿Cómo la filosofía puede ayudar a liberarnos de las alienaciones originadas por los sistemas de dominio y exclusión doscientos años después de los procesos independentistas del primer cuarto del siglo XIX? En aquellos años, América Latina realizó un proceso político denominado 'guerras de independencia' que puso fin al gobierno imperial español. Fue un enorme paso que nos dio cierta soberanía política, pero no fue suficiente, como todos sabemos, para acabar con el sistema colonial en su conjunto. La 'deuda de la independencia' con el imperio inglés y las deudas contemporáneas con los organismos multilaterales, sumadas al subdesarrollo general del subcontinente nos crearon y nos siguen creando una dependencia económica que no ha logrado ser superada todavía y que se manifiesta ahora mismo en una inequitativa transferencia de valor de los países hegemónicos hacia los países dependientes y un muy limitado acceso a la tecnología y la ciencia. El capitalismo avanzado y globalizado que se nos filtra por todo lado y el escaso acceso al desarrollo científico y tecnológico constituyen los nuevos nombres de un antiguo sistema de dominio que en el caso de América Latina y Ecuador dura ya cinco siglos.

\section{Encuadramiento del tema}

El sistema de dominio se desglosa y reproduce en alienaciones múltiples de orden económico, político, social y cultural que configuran nuestra vida cotidiana. Las diversas ciencias sociales dan cuenta de ellas y sugieren mecanismos para superarlas. Como filósofos, es el sistema como tal el que nos preocupa y el que debe ser pensado. En las décadas de los sesenta y setenta del siglo pasado, inspirados 
y estimulados por las revoluciones cubana y nicaragüense, creíamos que la transformación del sistema de dominio era posible. Pero el fracaso de ciertos intentos revolucionarios como el de Bolivia y de la misma Nicaragua y una ola de gobiernos militares y represivos crearon la convicción de que las condiciones objetivas requeridas para la revolución soñada o no existían o eran insuficientes. Sin embargo, lo que la filosofía y la teología de la liberación pensaron entonces se constituyó en un momento significativo del pensamiento latinoamericano. La reacción militarista del sistema no logró eliminar, a pesar de los intentos que hizo, las manifestaciones que pensaban las condiciones de posibilidad de una realidad transformada y una historia nueva.

Ese testimonio liberacionista del último cuarto del siglo pasado se sumaba al pensamiento emancipador que venía de Bartolomé de las Casas y su Brevísima relación de la destrucción de las Yndias Occidentales (1552), de Antonio de León Pinelo y El paraíso en el Nuevo Mundo (1650), de Eugenio Espejo y su Primicias de la Cultura de Quito (1792), de Simón Bolívar y la Carta de Jamaica (1815), de Simón Rodríguez y Las sociedades americanas de 1826 (1826), de Juan Bautista Alberdi y sus Ideas para presidir a la confección del Curso de Filosofía Contemporánea (1840), de Francisco Bilbao y El Evangelio Americano (1864); de José Martí y Nuestra América (1891), de José Lezama Lima y La expresión americana (1969). A estos testimonios se añadirían aportes contemporáneos como los de Enrique Dussel y su Ética de la liberación (1998) y de Arturo A. Roig y su Ética del poder y moralidad de la protesta (2002). Estos autores y libros constituyen la columna vertebral del pensamiento emancipador latinoamericano y hay indicios, bastante reales, de que tal pensamiento asciende cada vez más a su realización histórica concreta. 


\section{El papel de la filosofía}

El pensamiento filosófico actual no puede ignorar tales aportes. Al contrario, pensamos que el trabajo de los actuales filósofos latinoamericanos debe recoger la inspiración de aquellos autores y buscar, a su vez, las posibilidades reivindicativas insertas o diseminadas en el tiempo y la historia que nos ha tocado vivir. Si aquellos aportes brotaron coetáneamente a los sucesivos despliegues del sistema imperial, hoy deberíamos pensar las posibilidades de resistencia, crítica, impugnación y liberación frente a los actuales despliegues del capitalismo neoliberal globalizado vigente en nuestro contexto. A los filósofos actuales nos corresponde pensar las condiciones de posibilidad de eso que se ha llamado y se llama 'la segunda independencia'.

¿Qué puede proponer la filosofía en tanto pensamiento crítico frente a la actual 'colonialidad del ser, del poder y del saber'? La presente propuesta, que se ubica dentro de lo que podría llamarse una 'filosofía para la liberación $^{\prime 1}$, parte de experiencias latinoamericanas vigentes, como por ejemplo: el desconocimiento de nosotros mismos, la autodesvalorización, el extranjerismo, la alienación, la pobreza, la desconfianza, el sentimiento de inferioridad, la falta de oportunidades, la migración, la exclusión... Estas experiencias revelan un modo de ser in-satis-factorio (in-satis-factum = no suficientemente hecho), es decir impedido de realizarse con plenitud, libertad y autenticidad. Tales impedimentos imposibilitan el despliegue de valores originarios (como la autoposesión o propia pertenencia, el amor por la propia constitución, el cuidado de sí, el conocimiento de sí, la autovaloración, el autodominio, el libre albedrío), afectan a la existencia en cuanto tal (a nuestro rango ontológico y propia definición) y se manifiestan en nuestros modos cotidianos de vivir y organizarnos. 
La filosofía debe posibilitar un modo de pensar y vivir críticos frente al modo de vida alienado y al pensamiento único generados por el sistema. Pensar críticamente significa encontrar los límites del sistema vigente; es decir, esclarecer racionalmente los mecanismos y las formas de la alienación con miras a su superación. Vivir críticamente significa esforzarnos por re-apropiarnos y reconstituirnos y encontrar las vías racionales de solución de los problemas que la alienación determina. La filosofía es la vía adecuada para develar un principio de inteligibilidad (que los griegos llamaron $\log o s$ ) que permita re-constituirnos como seres humanos mediante mecanismos de desalienación y re-configuración de nuestra existencia y del sentido de nuestra vida.

\section{Las determinaciones estructurales}

¿Cuáles son esas estructuras que someten y postran a las grandes mayorías latinoamericanas y mundiales? Jon Sobrino, teólogo, nos lo indica: "Imperio e imperialismo parecían palabras muertas, pero la realidad las ha resucitado. Hoy no basta hablar de opresión y capitalismo para describir la postración de las grandes mayorías del mundo. El Norte y las multinacionales lo someten, como no se había conocido antes. Y de manera muy especial Estados Unidos. Es el imperio actual. Impone su voluntad sobre todo el planeta, con un poder inmenso, guiado por el pathos del triunfo, en todos los ámbitos de las realidades y a través de todo: economía que no piensa en el oikos, industria armamentista y su control, comercio inicuo e injusto, información manipulada o mentirosa, guerra cruel, terrorismo con apariencias legales y barbarie sin miramientos, irrespeto y desafío al derecho internacional, violación de 
los derechos humanos cuando es necesario, destrucción de la naturaleza...".

¿Frente a esta realidad de dominio, que se ampara también en una filosofía imperialista, qué puede proponer una filosofía liberacionista? ¿Cómo ésta puede ejercer su naturaleza crítica? La respuesta sería: deconstruyendo -en primer lugar- la razón imperial desde nosotros y desde las víctimas de cualquier parte, con el objetivo de desmontar sus argucias y criticar su lógica, su metafísica, su antropología, su ética; esclareciendo -en segundo lugar- los pensamientos, visiones, valores y compromisos que generen en nosotros un espíritu de lucha basado en la dignidad de cada uno y de todos, en la justicia social y equidad, en la autonomía, la soberanía, la interculturalidad, la transculturalidad, la visión planetaria, y la trascendencia; y proponiendo -en tercer lugar- lo que podría llamarse una 'conversión existencial' que permita mirarnos (más allá del ocultamiento del sistema), re-posicionarnos en la existencia auténtica, re-apropiarnos, conocernos, valorarnos y cuidar de nosotros mismos.

"El imperialismo -continúa Jon Sobrino- penetra en los seres humanos con la seducción, para unos pocos, y el engaño, para las mayorías, de la llamada 'cultura estadounidense', the american way of life. Ésta impone dos visiones de la vida muy poderosas: el individualismo, como forma suprema de ser, y el éxito como verificación última del sentido de la vida. Nos lo ofrecen -y nos lo imponencomo lo mejor que ha producido la historia. Y, a la inversa, fraternidad, compasión y servicios son productos culturales secundarios, tolerados, pero no promovidos"3.

¿Qué hacer frente a esta penetración del imperialismo en el alma, en la razón, en la conciencia, en la mente, en el espíritu, en la moralidad, en el sentido de libertad, en la cultura? El 'éxito', al modo imperialista, es la última de 
las seducciones del sistema y constituye una nueva alienación en contextos emergentes. Para que el 'éxito' se convierta en un modo de nuestra propia realización debemos des-colonizar nuestro ser, re-constituir nuestra condición ontológica. Sólo entonces, el 'éxito’ será una manifestación del despliegue de nuestro ser y no una mala copia de ajenos modos de ser. La filosofía puede/debe hacer bastante en este campo liberándonos del individualismo neoliberal, abriéndonos a la fraternidad y a la solidaridad, y re-constituyendo de este modo nuestro ser.

\section{Competencias necesarias para la re-constitución de nosotros mismos}

Los objetivos de este proceso reivindicativo serán la autorrealización, la conciencia de-si-para-sí, el amor al trabajo re-constitutivo de nuestra condición de sujetos (o subjetividad), el mejoramiento permanente a través de resultados tangibles y medibles. Las metas serán las de desarrollar saberes autorreferidos así como destrezas y habilidades para la vida, basados en competencias mentales, de la voluntad, cívicas y de convivencia con los demás (individuos y culturas). Estas competencias que, dicho sea de paso, deberían desarrollarse también a través del sistema educativo, son:

Competencias de la razón intuitiva: sirven para intuir nuestra propia existencia, para 'vernos' y realizar el 'giro o conversión existencial' que permite re-apropiarnos y cuidar de nosotros mismos. La propiedad y el cuidado de nosotros mismos posibilitan nuestra orientación en el contexto y la planificación estratégica de nuestra vida, con el objeto de autoconstruirnos cada día, de alcanzar los objetivos y las metas que nos hayamos propuesto, de autoevaluarnos, reorientarnos, recomenzar de ser el caso. 
Competencias de la razón cognitiva: sirven para pensar, conocer, comprender, interpretar, argumentar, explicar, juzgar, analizar, sintetizar, dudar, investigar, afirmar, negar... Estos parámetros, vistos desde la perspectiva de la razón epistémica (o de los saberes científico-técnicos) implican: conocer nuestra estructura biológica y humana y nuestra identidad terrena (biología, anatomía); posicionarnos en el mundo y en la historia (geografía, historia, geopolítica); hablar y comunicarnos (lenguaje); conocer el conocer y el calcular (desarrollo del pensamiento, matemáticas); entrar en la economía y en la sociedad (sistemas económicos y sociales vigentes y/o alternativos); participar en la política y en la cultura (sistemas políticos y culturales vigentes y/o alternativos); vivir la dimensión del cambio, la incertidumbre y la complejidad (pensamiento complejo); obrar ética y cívicamente (ética ciudadana, civismo).

Competencias de la razón dialéctica: requeridas para desarrollar una razón anti-imperialista y para saldar cuentas con el pasado en el sentido de asumirlo como un referente preñado, no sólo de lastres o taras descalificadoras, sino de 'futuros sidos': futuros que se previeron, soñaron o desearon en el pasado y que debemos re-constituirlos y re-posicionarlos como referentes que nos permitan saber hacia dónde debemos caminar. Estas competencias se requieren, además, para argumentar dialéctica, política y contraculturalmente en busca de síntesis que relancen permanentemente nuestros procesos de historización y rehumanización.

Competencias de la voluntad y del espiritu: necesarias para vivir, trabajar, producir y ser feliz. Abarca el ámbito de las profesiones, artes, oficios y toda actividad destinada a la producción de productos o servicios que, aunque no lo parezca, supone también el ámbito del pensamiento, de las ilusiones, de las utopías. Estas competencias per- 
miten desarrollar y cultivar expresamente, en contextos emergentes, el espíritu de lucha y de esfuerzo sostenido, la tenacidad, el empeño y el heroísmo cotidiano y, a la vez, el equilibrio y el autocontrol.

Competencias emocionales: sirven para indignarnos con lo dado, para sentir, desear y transitar el camino del re-descubrimiento de nosotros mismos, de nuestra reapropiación, re-centramiento, re-conocimiento, autorreferencialidad, autoconstrucción, autoestima, autocontrol, es decir sirven para la 'descolonización de nuestra subjetividad' y para el 'duro trabajo' de nuestra re-constitución y re-humanización.

Competencias éticas y cívicas: aluden a las responsabilidades propias del ser-con-otros o con-vivir, pues los 'otros', las otras culturas, nos constituyen esencialmente. El vivir-con o con-vivir es un modo de existir que capacita a las personas para las responsabilidades y la práctica de los valores éticos y cívicos, y para la fundamentación teórica de los mismos.

Competencias y destrezas auxiliares: tienen que ver con aprendizajes y destrezas de carácter instrumental, pero necesarias para nuestra re-constitución como seres humanos dignos y productivos: competencias y destrezas idiomáticas, informáticas, tecno-científicas, estéticas, por ejemplo.

Tales competencias, adecuadas a esta época de cambios, globalización, productividad y competitividad, suponen la determinación inclaudicable de ser y hacernos a nosotros mismos mediante la 'conversión o segundo nacimiento', el 'cuidado de sí y de nosotros mismos' y 'la superación permanente de los propios logros': giros existenciales que permiten superar las lógicas del sistema y que configuran el buen-vivir y el buen-morir. Desarrollar esas competencias y vivir según ellas es re-construir las bases 
ontológicas, antropológicas, epistemológicas, éticas y políticas de nuestra condición de sujetos, es re-construir el sentido de nuestra vida y de nuestra muerte. Esa es la verdadera travesía de nuestra libertad que en la práctica discursiva de este tiempo busca ponernos como el referente legítimo de nuestra existencia, de nuestra historia, de nuestro pensamiento, de nuestro desarrollo material y perfeccionamiento espiritual. Tal autorreferencialidad no nos encierra sino que identifica un logos, un modo de vernos y de ver el mundo que, por su propia naturaleza, está abierto a la relación heterónoma con otros individuos, con otros países, con otras culturas, con otros mundos.

\section{La subjetivación o el proceso de nuestra re-constitución como sujetos}

El camino recorrido por América Latina desde el siglo XVI hasta nuestros días abre posibilidades a la 'subjetivación' o re-construcción de nosotros mismos como sujetos históricos. Tal re-constitución determina el sentido general de nuestra vida y de nuestra muerte, pues implica nuestra tenaz persistencia en la existencia (a priori ontológico), el desarrollo de nuestra autoconsciencia (a priori antropológico), nuestra autovaloración y autocomprensión como fines y no como medios (a priori ético-axiológico), y la lucha por nuestros 'derechos' ante el sistema capitalista, neo-liberal y oligárquico (a priori ético-político $)^{4}$. Esta 'subjetivación' determina igualmente la necesidad de relacionarnos con otros individuos y otras culturas en términos de igualdad y mutuo respeto. La clave de este re-diseño existencial está en vernos, comprendernos y asumirnos como una experiencia histórica particular y específica, capaz sin embargo, de enriquecer y ser enriquecida con otras experiencias históricas distintas. 
Todo este proceso de 'subjetivación' significa que la invisibilidad, alienación, desvalorización y deshumanización que pesan sobre nosotros como determinaciones estructurales del sistema pueden ser revertidas mediante eventos existenciales que están al alcance de todos y cada uno de nosotros, como la 'conversión existencial', el esclarecimiento de saberes epistémicos e históricos y el desarrollo de un ethos que posibilite el reconocernos, desalienarnos, valorizarnos, humanizarnos. Este proceso constituye nuestra 'verdad' entendida en su más genuino significado: como desocultamiento (alétheia), como desvelamiento, como revelación o emergencia de nosotros mismos.

ara superar la 'colonialidad del ser, del poder y del saber' requerimos de: a) un 'giro ontológico' (conversión o segundo nacimiento); b) un 'giro antropológico' (nuestra re-constitución como sujetos históricos); c) un 'giro epistemológico' (uso de la razón por sí mismo y no por otro); d) un 'giro ético-axiológico' (re-apropiación y cuidado de nosotros mismos); y e) un 'giro político' (nuestra re-constitución como ciudadanos). Estos 'giros' generan posibilidades para una existencia autocentrada y responsable, para la trascendencia o superación permanente de nosotros mismos, para dejar un legado que justifique nuestro paso por el mundo, para enfrentar a la muerte como acto supremo de la vida, y para sobrevivir por siempre en una suerte de aurea aeternitas.

Si mediante la filosofía accedemos a estos núcleos existenciales configuradores de sentido y significado, podremos consolidar un modo de ser y de estar, de pensar y de actuar, de vivir y de morir basado en la centralidad de nosotros mismos en tanto nosotros mismos, es decir en tanto existencia individual y colectiva, histórica y empírica, autorreferida y valiosa en sí misma y por sí misma. Es la posibilidad histórica de estos a priori lo que nos ofrece- 
rá la oportunidad de darle un marco filosófico a nuestra autoafirmación como individuos, como sujetos históricos, como realidades múltiples y diversas. Esa será nuestra diferencia.

\section{La re-constitución ontológica o la persistencia en el ser (a priori ontológico)}

La inquietud de sí, intuición de sí, conversión, giro existencial, segundo nacimiento, vienen postulados por la propia historia y requieren de un expreso trabajo de nuestra razón para decodificarlos y asumirlos. De esta decodificación y asunción depende el acceso a los fundamentos últimos de nuestro ser. ¿Cómo percibir esa 'inquietud de sî́, 'intuición de nosotros mismos', 'conversión' o 'segundo nacimiento'? Para hacer visible este acontecimiento originario podemos utilizar dos caminos: uno que proviene de la filosofía y, otro, de nuestra experiencia histórica.

\subsection{El camino de la filosofía}

La 'intuición de sí/de nosotros mismos' es una experiencia originaria que se presenta a raíz de problemas existenciales o situaciones límites que comprometen nuestra vida toda: alienaciones sistémicas o individuales, enfermedad, sufrimiento, pobreza, marginalidad, migración, exclusión... Tales situaciones existenciales pueden ser examinadas por una suerte de hermenéutica existencial que permite pensar, comprender e interpretar el ser, la existencia, la vida y la muerte. Si nacemos en el seno de la alienación y la inautenticidad y éstas afectan a la globalidad de nuestra existencia, ¿cómo hacer para enfrentarlas?

La alienación afecta a nuestra definición de seres humanos al degradarnos ontológicamente y convertirnos 
en 'objetos a la mano' y en 'valor de cambio'. Las propiedades originarias de nuestro ser (que según los estoicos son: propia pertenencia, amor por nuestra constitución, cuidado de nosotros mismos, aceptación de lo que favorece a nuestra existencia y rechazo de lo que la afecta) quedan afectadas con la trágica consecuencia de la desapropiación de nosotros mismos. Nuestros componentes esenciales (animalidad, racionalidad, vida psíquica, vida espiritual) han sido separados, desconectados y desvirtuados (recuérdese que en el siglo XVI los conquistadores españoles dudaron que los indígenas tuvieran alma racional y, en el siglo XXI, se duda igualmente que seamos una muestra de racionalidad, madurez, democracia o progreso).

La desintegración de estos componentes esenciales de nuestro ser constituye un mal ontológico que se refleja en nuestra alma (razón, conciencia) y que, a veces, aflora también como 'enfermedad' del cuerpo. ${ }^{5}$ De las enfermedades del cuerpo se ocupa la medicina, de las alienaciones ('problemas existenciales', 'males del alma', 'asesinatos éticos', 'desintegración espiritual') se ocupa la filosofía mediante la elucidación de las determinaciones últimas de nuestra realidad y la intuición del valor de nuestra existencia y propiedades originarias (persistencia en el ser, propia pertenencia, amor por nosotros mismos, etcétera). Se trata entonces de una real 'descolonización de nuestra subjetividad': tarea ontológica que tiene la virtud de re-posicionarnos en la existencia, en la vida, en el pensamiento, en la acción, la pasión y la muerte.

Este compromiso esencial con nosotros mismos explora los modos de la razón que permiten desocultarnos, vernos, valorarnos y re-constituir nuestra unidad originaria. Los griegos llamaron logos a esto: un modo de la razón que les permitía comprender el mundo, mirarse a sí mismos, verse integralmente, conocerse a sí mismos, 
ser prudentes, buscar la serenidad del alma y la felicidad: tareas que constituían su filosofar. Nuestro filosofar tiene igualmente la finalidad de hacer posible la emergencia de nuestro propio logos: un principio de inteligibilidad que posibilite superar la alienación esencial y re-constituir la integridad y valor originarios de nuestra existencia. Esta 'vuelta a nosotros mismos' es el resultado del 'duro trabajo de nuestra subjetividad', del esfuerzo racional y político mediante el cual llevamos adelante las tareas de re-fundamentación de nuestra existencia y de nuestros modos de conocer, elegir, actuar, vivir y morir.

¿Con qué tareas la filosofía hace posible la emergencia del logos en nuestras vidas, un logos que permita lo que Platón llamaba 'conversión' y que, para nosotros, significa la posibilidad de vernos, re-apropiarnos, re-constituirnos, re-valorizarnos? Con las siguientes:

- Prestando atención, en primer lugar, a la angustia existencial que aflora en nuestra in-satis-facción original o imposibilidad/posibilidad de ser que nos acosa cada día; eso llevará a escuchar la 'inquietud de sí que brota desde dentro de nosotros mismos -verdadera 'llamada del ser', como diría Heidegger- y a acoger nuestro deseo originario de explicación y sentido que reclama condiciones objetivas y subjetivas para la realización individual y colectiva.

- Preocupándonos, en segundo lugar, por nosotros mismos, lo cual llevará a conocernos y cuidar de nosotros mismos -una verdadera ética del 'cuidado de sî'-; a procurar nuestra autonomía, autorreferencialidad, autovaloración y soberanía; a asumir el desafío de pensar por nosotros mismos -sapere aude- $\mathrm{y}$ de aprovechar el tiempo -carpe diem-.

- Superando, en tercer lugar, el simple 'sí mismo' (yo) por el 'Sí' re-flexivo (como diría Ricoeur), capaz de 
actualizar la alteridad que fecunda la existencia y nos convierte en 'nosotros'.

- Trascendiéndonos, finalmente, entrando en un proceso permanente de superación de lo dado o lo impuesto en busca de un florecimiento humano que sea la manifestación de nuestra integralidad materia-vida-conciencia-espíritu.

Esta re-constitución de nuestra subjetividad recrea las condiciones necesarias para el re-conocimiento y re-valorización de nosotros mismos; para el examen de nuestra vida; para la re-educación de nuestra mente y el cuidado de nosotros mismos; para el aprecio de lo bueno, lo mejor, lo bello y lo grandioso desde perspectivas propias y autónomas; para la transmutación de los valores impuestos, la deconstrucción de paradigmas, la re-semantización del lenguaje colonial; para, en fin, el 'giro existencial' que nos permite encontrar aquello que los pensadores antiguos, tanto de la filosofía asiática como de la europea, llamaron justo-medio-de-la-justicia, y que para nosotros, los del 'Sur', tiene nombres como re-apropiación de nosotros mismos, autoposesión, autorreconocimiento, autovaloración, autorreferencialidad, autonomía, soberanía, alteridad, interdependencia, interculturalidad, transculturalidad y visión planetaria.

\subsection{El camino de la experiencia histórica:}

Ecuador encuentra en la emergencia indígena acaecida en las últimas décadas del siglo XX un referente de lo que venimos llamando intuición de sí, giro existencial y re-constitución ontológica. Ocurre que la dinámica de nuestros procesos históricos se desplazó del agro a las ciudades con lo cual el eje del dominio que se sustentaba en la explotación de los indígenas pasó a ejercer su poder con otros grupos subalternos, como los marginales urba- 
nos, el incipiente proletariado o los inmigrantes internos. Ese 'avatar' hizo que la mirada del dominador se desplazara por un segundo, tiempo suficiente para que los indígenas pudieran ver su propia sombra, al principio, y, luego, después de cuatro siglos, pudieran verse a sí mismos.

Ese desplazamiento del eje del dominio de un grupo social a otro fue aprovechado por los indígenas, no para salir del sistema, pero sí para re-descubrirse, re-conocerse y encontrar valor en su propia etnicidad, en su cultura, costumbres y modos de ser. Más allá de su condición de 'folklore' al que les había condenado el sistema, los indígenas se re-conocieron y re-valorizaron como grupos étnicos significativos en sí mismos y por sí mismos. Estos grupos encontraron en ese nicho de la historia la posibilidad de intuirse, de verse y experimentarse a sí mismos como sujetos de derechos y no, sólo, como mano de obra barata, como esclavos o huasipungueros sin valor, al punto que habían sido vendidos como aditamento de las haciendas. Ese verse y re-descubrirse como seres humanos y como sujetos históricos constituyó un giro existencial que los sacó, en su conciencia y en sus propios modos de entender, de la cosificación a la que habían sido sometidos por siglos y los llevó a un re-posicionamiento ontológico. Tal re-posicionamiento no significaba un paso del no-ser al ser, o del 'ente' al 'ser' (lo que habría significado una 'diferencia ontológica' en la visión de Heidegger) sino una superación de su condición de 'objetos' y una re-definición como 'sujetos', luego de cuatrocientos años de 'resistencia'. Superaron de ese modo la alienación identitaria, se re-asumieron como indígenas, se sintieron orgullosos de su condición de indígenas, se organizaron y empezaron a reclamar con una voz que les salía de sus orígenes, los derechos y el espacio socio-económico-político que se les había negado sistemáticamente. Lo que vendría después, su organización a nivel 
nacional, su estructuración como partido político, su lucha por espacios de poder, sus demandas de infraestructura, de educación bilingüe, etcétera, serían las consecuencias de ese re-posicionamiento ontológico en el seno de una sociedad que, en momentos extremos, les había negado no sólo su condición de 'sujetos' sino hasta su condición de seres humanos.

¿Quiere decir esto que los indígenas se han liberado del sistema colonial vigente en América Latina y Ecuador? No. Han superado en el plano de las comprensiones identitarias los mecanismos de deshumanización, invisibilización y desvalorización que el sistema empleó en su contra desde el siglo XVI y han pasado de su condición de animales de trabajo o fuerza bruta a la condición de seres humanos y sujetos de derechos. Eso no es poco, es el paso histórico sin el cual no puede darse el cuestionamiento y lucha contra el sistema. Re-posicionarse en el ámbito de lo humano y de lo histórico ha significado para los indígenas liberar las posibilidades de autoconstruirse como 'espíritu' (como razón, mente, conciencia, libertad, moral, cultura), capaz de superar las determinaciones de la colonialidad para pasar a ser dignos de autodirigirse y autodeterminarse.

En la lucha contra la 'colonialidad del ser, del poder y del saber', estamos todos: indígenas, mestizos y afroamericano, pero cada sector tiene la responsabilidad de re-hacerse a sí mismo de acuerdo a las determinaciones socio-histórico-económico-políticas que le ha tocado vivir. La re-constitución indígena constituye, en todo caso, un referente que los otros grupos sociales de nuestro contexto no deben ignorar. Se trata, efectivamente, de una experiencia histórica iluminadora que, aunque no sea tomada como un modelo porque cada sector social tiene que hacer su propio proceso, sirve como referente de la 'conversión', 
'giro existencial' o 'segundo nacimiento' requerida en el ámbito ecuatoriano y latinoamericano.

\section{La re-constitución antropológica o la subjetivación (a priori antropológico)}

El 'giro existencial' o "segundo nacimiento" posibilita la desalienación y supera el estado de desapropiación, desconocimiento y desvalorización de mí mismo y de nosotros mismos. Si por el 'primer nacimiento' vinimos al mundo, por el 'segundo nacimiento' advenimos a nosotros mismos, re-nacemos para nosotros mismos, nos hacemos visibles.

Luego de 500 años de alienación durante los cuales el sistema nos invisibilizó y alejó de nosotros mismos y mediante la re-lectura del 'legado' reconstitutivo y reivindicativo de las generaciones anteriores que lucharon contra aquella, yo/nosotros apelamos a nuestra pertenencia natural y originaria y nos re-descubrimos como existencia en proceso de re-cuperación. A esto hemos llamado 'giro existencial' y el mismo se sustenta tanto en el impulso natural de los seres vivos a la propia pertenencia (a amar la propia constitución y a cuidar de sí mismos, a procurarse lo que favorece a su existencia y a desechar lo que la dificulta o perturba $)^{7}$, como en la tenacidad histórica por ser nosotros mismos (que posibilita superar la condición de 'objetos' impuesta por el sistema y transformarnos en 'sujetos'). Éste, hemos dicho, es el primer paso en la construcción de una subjetividad descolonizada, como seres humanos y como grupo social emergente.

Esta 'des-alienación de nuestra existencia' o 'descolonización de nuestra subjetividad' es, en sí misma, una práctica de liberación, re-constitución y re-valorización. Es esta práctica la que hace que los individuos o los pue- 
blos se experimenten como dueños de sí, autónomos, soberanos, autosuficientes, sin menoscabo de las necesarias interrelaciones con los demás. Por ello, el 'giro existencial' no empieza por ser un mero pensamiento o idea sino una intuición autofundante (captación inmediata de sí mismo/ nosotros mismos), una 'conversión' que nos permite pasar de la desapropiación generada por el sistema a la re-apropiación de nuestra existencia histórica.

Los 'giros existenciales' no sólo generan la necesidad de autoconstruirnos, sino también la necesidad de superar permanentemente nuestros propios estándares. A eso llamamos 'trascendencia'. Trascender no significa en este caso el pasar de un ámbito o nivel a otro (paso del ámbito de lo sensible al de lo inteligible, por ejemplo, en Platón), significa superar los propios logros, entrar en la senda del mejoramiento antropológico con miras a la perfección (inalcanzable por definición pero que debe funcionar siempre como un referente), no detenerse complacientemente en el camino de la autorrealización individual (al estilo de las autoayudas) ni claudicar jamás en la voluntad de ser y acontecer. Este mejoramiento sostenido se basa en aprendizajes (aprender a mirarnos a nosotros mismos, a conocernos, a valorarnos, a partir siempre del contexto, a administrar el presente sin negar el pasado ni cerrar el futuro, a vivir y convivir, a ser y hacer) y hábitos (de la autorreflexión, la autorreferencialidad, la autoconstrucción, la apertura a los Otros, la solidaridad, la meditación, el diálogo, la rememoración, el prepararse para la muerte...) que nuestro sistema educativo debe propiciar. 'Trascendencia' es, en suma, la superación cotidiana de sí o de nosotros mismos, que supone una intuición fundante, un plan de vida, proyectos, metas y la tenaz voluntad de mejorar, siempre. 


\section{La re-constitución epistemológica o la theoría, la visión y el conocimiento de sí (a priori episte- mológico)}

La theoría que saca a luz el modo de conocer los fundamentos originarios del ser y existir en contextos signados todavía por la colonialidad y la emergencia requiere tanto de 'saberes epistemológicos' (que tienen que ver con la razón pensante) como de 'saberes históricos' (provenientes de nuestra experiencia histórica, de nuestra cultura -paideia-, y de nuestro 'espíritu').

\subsection{Los nuevos saberes epistémicos}

Los saberes de la razón, necesarios en contextos emergentes para la transformación personal, constituyen conocimientos de carácter epistémico, suponen reflexión, crítica y autocrítica, análisis y síntesis, categorizaciones, conceptos, etcétera. Son equiparables al conocimiento científico actual y pueden conducirnos a la esencia del mundo y de la vida. Tales saberes son:

La 'doble crítica': alude al talento, destreza o habilidad de nuestra razón para 'ver' (sacar a luz, hacer patente, conceptuar, sistematizar) lo ocultado por la 'colonialidad del ser, del poder y del saber': nosotros mismos como sujetos emergentes en lucha por la descolonización. Si lo que llamamos 'crítica' consiste habitualmente en ver sólo el 'envés' del sistema como obnubilación, ocultamiento y desvalorización de nosotros mismos; la 'doble crítica' consistirá en ver también el 'revés' del sistema donde emerge la posibilidad de re-descubrimos, re-apropiarnos, autoafirmarnos, autovalorarnos.

El autoconocimiento y la personalización: el autoconocimiento alude a la investigación racional acerca de 
nosotros mismos, acerca de nuestra persistencia en el ser y en la existencia (el conatus de Spinoza), acerca de nuestras necesidades y demandas históricas y de los imperativos de nuestra realidad social emergente. La personalización requiere de procedimientos racionales autorreferidos (autorrealización, autoconstrucción y autovaloración) que ponen ante los ojos el nivel existencial en el que se encuentran los individuos y las colectividades: supervivencia, resistencia, identidad, desarrollo, bienestar, solidaridad, ....

La contextualización y globalización: el contexto configura nuestra constitución personal y nuestra identidad, por eso las tareas decoloniales suponen un conocimiento del contexto con el objeto de que los sujetos emergentes puedan explorar, conocer y dominar su 'territorio' y realizarse en él. El contexto no es un ámbito cerrado, es el conjunto de determinaciones sociales, económicas, políticas, culturales, materiales, espirituales y mentales desde las cuales nos interrelacionamos con el mundo y nos abrimos a la globalidad. Las tareas de descolonización suponen también conocimientos acerca del ordenamiento actual del mundo, de las geopolíticas vigentes tanto en el orden del poder como del saber, y de los mecanismos idóneos para nuestro posicionamiento en el mundo globalizado.

La complejidad y desideologización: las tareas de descolonización propiciarán la enseñanza/aprendizaje de 'lo que está tejido junto', es decir del mundo como un complejo interrelacionado, multicultural, multidimensional, transnacional, transdisciplinario, transversal, global, planetario, cósmico ${ }^{8}$. Pero, a la vez, la centralidad de nosotros mismos exigirá que lo "importado" (sobre todo los productos de pensamiento) sea re-semantizado, re-ajustado y re-funcionalizado de acuerdo a las condiciones de nuestro contexto y de nosotros mismos. 


\subsection{Los nuevos saberes históricos}

A partir del 'giro existencial', 'conversión' o 'segundo nacimiento' como experiencia originaria de carácter individual y social, necesitamos desarrollar los diversos modos de construirnos a nosotros mismos. La clave está en no perdernos de vista en medio de los laberintos y argucias de la razón enajenante hegemónica y de sus 'ciencias', todavía manipuladas por los sistemas de dominio. Los 'saberes' históricos que necesitamos para ello, son:

La visibilización, re-apropiación y autorreferencialidad: la visibilización es aquella intuición que permite captarnos como seres humanos, más allá del sometimiento y alienación infringida por el expansionismo, el colonialismo, la religión, la metafísica, el neo-colonialismo, la geopolítica, la ciencia, la tecnología, y las sucesivas culturas imperiales. La reapropiación de nosotros mismos implica el aprender a asumirnos como sujetos de derechos y no como objetos o cosas a la mano dentro del sistema hegemónico, para superar por esa vía la deshumanización y anonadamiento que condicionan todavía nuestra existencia individual y social. La autorreferencialidad nos re-sitúa en el orden humano poniéndonos como eje o referente fundamental de todo cuanto acontece en nuestra existencia individual o colectiva.

El conocimiento y cuidado de nosotros mismos: el conocimiento alude al hecho de tomar posesión de nosotros mismos mediante la razón, conocer nuestras posibilidades y límites, comprender la direccionalidad humanizante de nuestra historia, vislumbrar nuestra ubicación y sentido en el contexto y en el mundo, re-descubrirnos en fin no sólo como existentes, sino también como valiosos y fines en sí. El cuidado de nosotros mismos implica la conciencia de que somos nuestros propios dueños, que 
debemos -por ello mismo- amar y procurar lo que es favorable a nuestra existencia y rechazar todo cuanto la afecta, la aliena o la vuelve inauténtica.

La autonomía y soberanía: la autonomía alude al autocomprendernos y autorrealizarnos según las 'normas' de la existencia y dignidad humanas, válidas para el plano individual y social: propiedad de sí, cuidado de sí, conocimiento de sí, autovaloración, realización de un destino propio y autorreferido. La soberanía se refiere a la capacidad de gobernar/controlar nuestra existencia y nuestras decisiones y direccionarlas a nuestro mejoramiento permanente y a la excelencia.

La interdependencia e interculturalidad: la interdependencia permite comprender que la existencia es una relación de enriquecimiento recíproco con los demás, tanto a nivel de los individuos como de las culturas, pero también una relación con la naturaleza y el entorno histórico-cultural. La interculturalidad alude a la capacidad de viabilizar una relación igualitaria y mutuamente enriquecedora entre los componentes sociales y culturales de la realidad local (mestizos, indígenas y negros) y global (todas las culturas del mundo).

La transculturalidad y la visión planetaria: la transculturalidad impide convertir las culturas en espacios cerrados de existencia y posibilita la superación de los límites o bordes culturales a favor de comunidades cada vez más grandes y autosustentadas. La visión planetaria plantea que así como nosotros somos realidades históricas y sociales localizadas y específicas, hay otras múltiples y diversas realidades históricas y sociales más allá de nosotros, a las cuales debemos abrirnos con visión planetaria y con la expresa finalidad de enriquecer mutuamente los respectivos horizontes, sin renunciar a las propias especificidades. 
La trascendencia y la visión cósmica: la trascendencia alude a la necesidad de partir de lo que somos para mejorar y superar el nivel existencial en el que nos encontramos: eso nos lleva a la búsqueda de horizontes cada vez más amplios (globales, planetarios) para nuestro desarrollo y progreso, pero también más humanos para la convivencia y reciprocidad. La visión cósmica se fundamenta en la creciente certeza de que no estamos solos en el universo, lo cual nos impulsa a mantener una mirada abierta al cosmos, a ese ordenamiento que no depende enteramente de nosotros, pero del que formamos parte, lo entendemos y lo asumimos a partir de nosotros.

\section{La re-constitución ética o el ethos, la acción, la realización y el cuidado de si (a priori ético- axiológico)}

Si partimos de las necesidades y demandas del nuestro contexto y colocamos como valor fundamental el re-apropiarnos a nosotros mismos, el girar sobre nosotros mismos, el conocernos, el valorarnos y el construirnos individual y socialmente, podemos lograr que los 'conocimientos' esclarecidos en el nivel de la ' theoría' se transformen en 'ethos' y den lugar a nuevos valores que orienten nuestra realización y vida ética. Tendremos así la conjunción de conocimiento y ethos, de teoría y práctica, de paradigmas y valores, de conceptos y vivencias: ethos que representa la plasmación real del sujeto descolonizado y re-constituido, reivindicado y redefinido por sí mismo. ¿Cuáles son las características de este nuevo hombre latinoamericano? Veamos algunas de ellas:

Un sujeto descolonizado desarrolla la destreza mental de detectar o intuir que estamos en una situación histórica que produce alienación, deshumanización, subestima- 
ción, pero en lugar de percibirla como realidad inamovible, la percibe como necesidad y demanda de re-descubrimiento, re-apropiación, re-conocimiento y re-valoración de sí mismo y de nosotros mismos. En esta línea, el sujeto descolonizado identifica sin eufemismos las realidades objetivas en las que se reproduce la alienación y desvalorización (deuda externa; intercambio comercial desigual y deficitario; cultura mendicante; migración; educación alienante; escasa investigación científica; retraso en la producción de tecnología o en la utilización de la ya existente, etcétera) y lucha por criticarlas, por minimizar sus efectos, por generar otras oportunidades y alternativas. A la vez, el sujeto descolonizado saca a luz, con ayuda de la filosofía, las realidades subjetivas en las que se reproduce la alienación y deshumanización: la obnubilación de la mente; la carencia de proyectos, objetivos y metas globales; el conformismo; el descrédito, la frustración; la escasa iniciativa; la ineptitud o incompetencia; la inseguridad individual o colectiva; el desamor, el autojuzgamiento negativo; la desmotivación y apatía; la autodesvalorización; la tendencia a la inacción y a la pasividad; la excesiva reflexión o teorización y el poco pragmatismo; la tendencia a problematizar en lugar de solucionar; la ceguera mental que impide ver oportunidades; la baja autoestima; el miedo al fracaso; los conflictos emocionales irresueltos; la falta de voluntad y persistencia; la ausencia de planificación básica de la propia existencia; el sentido de solidaridad poco desarrollado; la negación o vergüenza del pasado; el desencanto con/de nosotros mismos; la incapacidad para visualizar el futuro, la soledad patológica...

Un sujeto descolonizado comprende que la resolución de estos problemas existenciales y malestares del alma no corresponde a los saberes epistémicos (psicología, medicina, conocimiento científico en general) sino a los saberes 
existenciales (saberes históricos, empíricos, reivindicativos, autovalorativos, ya descritos). Se posibilita de ese modo el desencubrimiento y la re-apropiación de nosotros mismos, el re-conocimiento, la autovaloración, la autorreferencialidad, la autonomía, la soberanía, la interdependencia, la interculturalidad, la transculturalidad, la visión planetaria, la trascendencia y la visión cósmica. Un sujeto descolonizado convierte estas necesidades históricas y retos presentes en acciones, en praxis autorreferida y re-constitutiva. Para ello distingue entre los referentes que tienen el aval de nuestra historia y los provenientes de otros contextos, que pueden ser 'tomados' solamente si nos 'apropiamos' de ellos, es decir, si los desabsolutizamos y desideologizamos.

Un sujeto descolonizado averigua siempre los ‘por qué?', los ‘cómo?’ y los ‘ipara qué?’ ¿Por qué desideologizar los referentes extraños (sistemas, modelos, ideas, personajes)? Porque todo producto 'importado', por grandioso que fuere, tiene que cumplir ciertos requisitos cuando llega, es invocado o convocado a un contexto que no es el suyo. ¿Cómo desideologizarlos? Ajustando el pensamiento 'importado' (que ha sido construido para satisfacer las necesidades de un contexto extranjero) a las condiciones de nuestro contexto, adecuándolo a nuestras necesidades históricas, calibrándolo con nuestros imperativos históricos y axiológicos, limpiándolo del 'contrabando' de significados ocultantes y desvalorizantes. ¿Para qué desideologizarlos? Para dejar expedita nuestra mente con el objeto de que pueda enfrentar, analizar, evaluar, adoptar, adaptar o rechazar cualquier modelo, sistema o teoría que cumpla o pretenda cumplir funciones ideológicas en nuestro contexto. De este modo, re-semantizamos tales conocimientos, los convertimos en un instrumento útil para nuestras propias construcciones teórico-prácticas y evitamos aceptarlos ingenuamente. Este sometimiento a las condiciones de 
nuestro contexto impedirá que la carga de significados que trae todo producto importado (sea intelectual o material) oculte, tergiverse o desvalorice nuestro mundo de símbolos y significados. ${ }^{9}$ Así nos volveremos expeditos en la relectura permanente de nuestros procesos históricos y del sentido liberador subyacente en ellos.

Un sujeto descolonizado cultiva la razón analítica (que separa, discierne, juzga) y sintética (que une, integra y conjuga): la finalidad apunta a que todo el proceso mantenga coherencia con el objetivo fundamental (la emergencia, desalienación, re-apropiación), sostenga el rumbo adecuado y evite que la brújula existencial se desvíe de su puerto de destino (nosotros mismos). A la vez, el sujeto descolonizado evalúa, compone y recompone, valora, aprecia las ventajas históricas de los procesos re-constitutivos de nosotros mismos: este entrenamiento desarrolla la capacidad de hacer altos estratégicos, elaborar balances existenciales y evaluar lo caminado en el camino que conduce hacia nosotros mismos.

Un sujeto descolonizado aprende a vivir con el cambio, la relatividad, la incertidumbre, la provisionalidad, la contingencia: los resultados del proceso son siempre transitorios (en tránsito hacia algo superior). Esta destreza se entrena con la observación del cambio permanente que existe en la naturaleza, en la sociedad y en la vida de cada uno y que se manifiesta a través de éxitos y fracasos, ascensos y caídas, avances y retrocesos, nacimiento y muerte, comienzos y re-comienzos. El cambio es una invitación cotidiana a trabajar por nuestro mejoramiento permanente, por un avance sostenido en nuestro proceso de autoconstrucción y autovaloración (en el plano individual y en el colectivo).

Finalmente, un sujeto descolonizado disfruta y es feliz en el proceso mismo de transformación del yo: el obje- 
tivo es alcanzar el florecimiento humano (que los griegos llamaban eudaimonía) que proviene de la autoposesión, cuidado y conocimiento de sí mismo y de nosotros mismos. El logro de este objetivo tiene la virtud de producir equilibrio y armonía entre todas nuestras 'facultades' (instintos, sentidos, voluntad, razón, espíritu).

\section{La re-constitución política o el buen-vivir, los derechos, la ciudadanía y el buen-morir (a priori ético-político)}

Esta re-humanización de nosotros mismos posibilita, a través de la reorientación de nuestras capacidades, saberes y competencias, el surgimiento de un horizonte político de liberación que tiene que ver con cuatro necesidades fundamentales de nuestra existencia: el buen-vivir, los derechos, la ciudadanía y el buen-morir.

El buen-vivir se relaciona con la necesidad de vencer a la muerte ética generada por la alienación del sistema. La vencemos con el 'segundo nacimiento, conversión o giro existencial' que, como ya lo hemos descrito, permite re-descubrirnos, apropiarnos de nosotros mismos, cuidar de nosotros mismos, conocernos, valorarnos, interrelacionarnos, trascendernos, ubicarnos en un horizonte planetario y cósmico. El 'ethos' requerido para esta 'conversión' se sustenta en hábitos y costumbres que son como mandamientos para la vida cotidiana y entre los cuales podemos mencionar: el re-conocimiento, que permite vernos y comprendernos como sujetos capaces de persistir en el ser y de construir el sentido que nuestra existencia requiere; la autorreferencialidad, que alude a nuestra condición de eje y referente, no único ni total y mucho menos hegemónico o unilateral, pero sí natural y primero, que pone por delante nuestra condición de seres humanos dignos y libres; la 
autoconstrucción, que alude a la responsabilidad de ser los arquitectos de nuestra propia existencia, capacitados para construirla con las normas de la propia identidad, del bien, de la verdad y de la belleza; la trascendencia, que alude a los movimientos existenciales que permiten 'pasar subiendo' -transcendere- del anonadamiento a la liberación de nuestro yo, de la alienación a la autoapropiación, de la 'subjetividad colonizada' a la 'descolonización de nuestra subjetividad', de la dependencia a la liberación, de la opacidad de las cosas a la mano a la luminosidad de lo que se sustenta en sí mismo y se mejora por propia iniciativa y voluntad, del nihilismo a la re-definición de valores auténticos y específicos, propios y 'apropiados', contextualizados y desideologizados.

Los derechos tienen la finalidad de garantizar que los latinoamericanos encuentren en su mundo de posibilidades aquellos que garanticen su supervivencia, su educación, su vivienda, su salud, su participación en la vida social, económica, política y cultural de su contexto. La idea es que todo ser humano encuentre en su horizonte existencial la posibilidad de hacerse y rehacerse, de vivir y convivir, de pensar y sentir, de dejar un 'legado' e inmortalizarse. Dejamos un 'legado' al aportar día tras día a la promoción de una existencia digna, equilibrada y feliz: único modo válido de incorporarnos al devenir permanente de la existencia universal que se perenniza en las existencias particulares y colectivas. La inmortalidad está ligada a lo que existe, a lo que es, al mundo y al universo (sea uno o múltiple) que devienen permanentemente y que en su devenir se degradan y perpetúan. Entrar en el ritmo de lo que se perpetúa a pesar de degradarse es entrar en la inmortalidad benéfica de lo que se regenerará por siempre. Eso es tener un alma racional ( $p s y c h e$ ), eso es trascenderse a sí mismo, eso es alcanzar la intemporalidad. 
La ciudadanía tiene que ver con la necesidad de construir desde el ámbito en el que cada uno se mueve, una democracia participativa, eficiente, abierta y solidaria. No se es ciudadano por pertenecer a un Estado, se es por participar en su construcción cotidiana, en su autodeterminación y soberanía. Las democracias liberales que representan la forma de organización política funcional a los intereses de las oligarquías locales e internacionales, obstaculizan la consolidación de democracias reales, participativas e igualitarias, basadas en la justicia, la equitativa distribución de la riqueza, las oportunidades para todos. En aquellas, la ciudadanía viene impuesta por el poder detentado generalmente por las clases hegemónicas; en las democracias reales, la ciudadanía viene dada por el empoderamiento de todos los miembros del Estado. Las condiciones para las democracias reales deben ser construidas y lo serán a medida en que América Latina avance en los procesos de subjetivación, de justicia, equidad y participación, es decir de liberación y ciudadanización.

El buen-morir tiene que ver con la necesidad de generar sentido para la muerte física. Lo hacemos mediante la construcción de ese 'legado' que, al medirse con los parámetros de la dignidad y los derechos humanos, promueve la realización individual y colectiva, el mejoramiento del alma humana, la expansión de lo equitativo, lo bondadoso, lo verdadero y lo hermoso. Este 'legado' cotidianamente construido en el pequeño ámbito en el que cada uno se mueve, le permite al hombre sabio y descolonizado morir en paz consigo mismo, es decir entrar en el torrente eterno de la existencia auténtica y de la vida digna y libre: un modo de perennización o inmortalidad que empieza a vivirse en esta misma vida. El sujeto descolonizado entiende la muerte no como un fin sino como un reciclarse permanente de la vida, que avanza por siempre: abre de ese modo 
la puerta de la eternidad, sea o no recordado cuando haya desaparecido de este mundo.

\section{Conclusión}

Jon Sobrino se planteaba la pregunta de qué hacer frente al imperialismo que nos llega con la geopolítica, el servilismo -más o menos inevitable- de los dirigentes y con el interés egoísta del capital, y también con excesos de sumisión en los pueblos. La respuesta que hemos intentado es: entrar en las tareas de descolonización de nuestra subjetividad, capaces de conducirnos a nuestra re-constitución ontológica, antropológica, ética y política y a la autocomprensión de nosotros mismos como fines en sí y no como medios, objetos o valor de cambio. En suma, nos corresponde pensar las condiciones para nuestra re-humanización a partir de un parámetro universal pisoteado por los imperialismos: la dignidad de sujetos autónomos, soberanos, interdependientes, interculturales.

Los caminos de liberación doscientos años después de las gestas independentistas del primer cuarto del siglo XIX están atravesados por aquellos aspectos esenciales que nos convierten en sujetos: la persistencia en el ser, la necesidad de pensar por nosotros mismos, la posibilidad de construirnos de acuerdo con 'normas' naturales, humanas e históricas. Ello conduce a nuestra liberación ontológica, epistemológica, ética y política, que hemos intentado describir. Este es el camino correcto hacia nosotros mismos y hacia nuestra dignidad de seres humanos, pensantes, libres y ciudadanos, solidarios e interculturales, que podemos esclarecer desde la filosofía. En esto consiste la anhelada 'segunda independencia'. 


\section{Notas}

1 La llamada 'filosofía de la liberación' tuvo y tiene nombres y apellidos concretos y corresponde a la generación de pensadores básicamente argentinos que organizaron sus aportes teóricos a partir de la década de los setenta del siglo pasado. En las décadas siguientes surgieron diversas críticas contra ese movimiento. Su representante más conocido es, sin duda, Enrique Dussel.

2 Cfr. Espiritualidad del anti-imperialismo, http://servicioskoinomia. org/relat/349/htm, p. 1

3 Cfr. J. Sobrino, Espiritualidad del..., p. 4.

4 A. Roig ha mencionado estos a priori en Ética del poder y moralidad de la protesta. La moral latinoamericana de la emergencia, Universidad Andina Simón Bolívar Sede Ecuador - Corporación Editora Nacional, Quito, 2002, p. 78.

5 La ciencia reconoce que muchas enfermedades físicas, como la gastritis, úlceras, cáncer, fibromialgia, etcétera, tienen un fuerte componente psíquico.

6 El concepto es de Hegel y ha sido resemantizado por varios autores para el contexto latinoamericano. Cfr. A. A. Roig Ética del poder y moralidad de la protesta..., Quito, 2002.

7 Los estoicos llamaron "oikéiosis" a esta 'norma' de la existencia humana y lo describieron en estos términos: “... inmediatamente al nacer una criatura viviente siente apego por sí misma y un mandamiento de preservarse a sí misma y de amar su propia constitución y las cosas que tienden a preservar esa constitución; mientras que, por otra parte, alberga antipatía por la destrucción y las cosas que encierren una amenaza de destrucción. Como prueba de ello muestran que los niños desean lo conducente a su salud y rechazan lo opuesto, aun antes de haber sentido placer o dolor; esto no sería así si no sintiesen amor por su propia constitución y no temiesen la destrucción. Pero sería imposible que sintiesen deseo si no poseyesen una conciencia de sí y, en consecuencia, si no se amasen a sí mismos. Esto lleva a la conclusión de que el amor a sí mismo procura el punto de partida". Cfr. Diógenes Laercio, Vidas de los más ilustres filósofos griegos, Ediciones Orbis, Barcelona, 1985, Vol. II, p. 67. Cfr. también Malcolm Schofield y Gisela Striker (comps.), Las normas de la naturaleza. Estudios de ética helenistica, Ediciones Manantial, Buenos Aires, 1993, p. 157.

8 Cfr. Edgar Morin, Introducción al pensamiento complejo, Barcelona: Editorial Gedisa, 1997, p. 167. 
9. Hay que recordar que la dominación contemporánea se da con mucha fuerza en el ámbito de lo simbólico. Cfr. Pierre Bourdieu y Loïc Wacquant, Las argucias de la razón imperialista, Editorial Paidós, Barcelona, 2001.

\section{Bibliografía}

BOURDIEU, Pierre y Loïc Wacquant

2001 Las argucias de la razón imperialista, Barcelona: Editorial Paidós.

LAERCIO, Diógenes

1985 Vidas de los más ilustres filósofos griegos, Barcelona: Ediciones Orbis, Vol. II, p. 67.

MORIN, Edgar

1997 Introducción al pensamiento complejo, Barcelona: Editorial Gedisa.

ROIG, Arturo Andrés

2002 Ética del poder y moralidad de la protesta. La moral latinoamericana de la emergencia, Universidad Andina Simón Bolívar Sede Ecuador - Corporación Editora Nacional, Quito, p. 78.

SCHOFIELD, Malcolm y Gisela Striker (comps.)

1993 Las normas de la naturaleza. Estudios de ética helenística, Buenos Aires: Ediciones Manantial, p. 157. 